Published in final edited form as:

J Obes Weight Loss Ther. ; 1(106): .

\title{
Evaluation of the Accuracy of a Triaxial Accelerometer Embedded into a Cell Phone Platform for Measuring Physical Activity
}

C U Manohar ${ }^{1}$, S K McCrady², Y Fujiki ${ }^{3}$, I T Pavlidis ${ }^{3}$, and J A Levine ${ }^{2, *}$

${ }^{1}$ Case School of Medicine, Case Western Reserve University, Cleveland OH 44106

Endocrine Research Unit, Mayo Clinic, Rochester MN 55905

${ }^{3}$ Department of Computer Science, University of Houston, Houston TX 77004

\section{Abstract}

Background-Physical activity is important in health and weight management. Several cell phone platforms integrate an accelerometer onto the motherboard. Here we tested the validity of the cell phone accelerometer to assess physical activity in a controlled laboratory setting.

Methods-31 subjects wore the cell phone on their waist along with the validated Physical Activity Monitoring System (PAMS) with different body postures and during graded walking. Energy expenditure was measured using indirect calorimetry. 11 subjects also wore the iPhone at different locations such as arm, hand, pant pocket, etc.

Results-The cell phone accelerometer was accurate and precise compared to the PAMS, with an intra-class correlation coefficient $\left(r^{2}>0.98\right)$. The cell phone accelerometer showed excellent sequential increases with increased in walking velocity and energy expenditure $\left(\mathrm{r}^{2}>0.9\right)$.

Conclusion-An accelerometer embedded into a cell phone was accurate and reliable in measuring and quantifying physical activity in the laboratory setting. Data from free-living users shows promise for deployment of a comprehensive integrated physical activity promoting and weight loss platform using such mobile technologies.

\section{Keywords}

Energy expenditure; Obesity; Weight loss; Physical activity

\section{Introduction}

For decades, experts have called for improved methods and tools for measuring daily activity [1] in order to clarify the role of physical activity in health and disease and to better define the effectiveness of strategies to increase it.

With the availability of low cost accelerometer chips that exploit Micro Electro-Mechanical Systems (MEMS) technology, a variety of commercial devices have become available that

Copyright: (C) 2011 Manohar CU, et al.

*Corresponding author: Dr. James A. Levine, Endocrine Research Unit, Mayo Clinic, Rochester MN 55905, Tel: 507-284-2511; Fax: 507-255-4828; Levine.james@ mayo.edu.

This is an open-access article distributed under the terms of the Creative Commons Attribution License, which permits unrestricted use, distribution, and reproduction in any medium, provided the original author and source are credited.

Disclosures: None of the authors have any potential conflict of interest to disclose. 
can measure daily physical activity. The devices, particularly when incorporating triaxial (x, $\mathrm{y}$ and $\mathrm{z}$ axis) accelerometers have proven valid when compared to measurements of total daily energy expenditure performed using doubly labeled water [2].

The greatest limitations of accelerometer-based devices are that (a) they are expensive, (b) they need to be continuously worn by the users, and they require skilled laboratory personnel to (c) access and (d) analyze the data.

One effective approach for measuring free-living physical activity could be to integrate a MEMS accelerometer into a preexisting electronic device such as a cell phone or portable music player. That is what we propose to test in this application.

There are several cell phone systems that have an accelerometer built into the motherboard of the phone; one such device is the iPhone (Apple Computer, Cupertino, CA). The advantage of exploiting the onboard accelerometer on the iPhone, in particular, is that this platform can be programmed by licensees. We wrote a software application to analyze the cell phone accelerometer data and chart the user's daily physical activity. In this study we evaluated the validity of the cell phone accelerometer in controlled laboratory studies.

The hypotheses we tested were:

- First, that the cell phone-Application is an accurate and reliable (Intraclass Correlation Coefficient $\mathrm{r}^{2}>0.75$ ), device for measuring physical activity compared to Physical Activity Monitoring System (PAMS) in the laboratory setting.

- Second, that there is a significant positive correlation $\left(r^{2}>0.75\right)$ between the cell phone accelerometer output and free-living activity energy expenditure measured using indirect calorimetry.

\section{Materials and Methods}

\section{Subjects}

We tested the cell phone accelerometer in 31 people (14 women), $33 \pm$ (SD) 9 years, $81 \pm 20$ $\mathrm{kg}$ and BMI $27 \pm 5 \mathrm{~kg} / \mathrm{m}^{2}$. Subjects were excluded if they smoked, were pregnant, had any acute or chronic illness, had unsteady body weight ( $>2 \mathrm{~kg}$ fluctuation over the six months prior to study), had a medical history of thyroid dysfunction or were taking medications capable of altering metabolic rate. Based on the body mass index (BMI), the subjects were classified in to three groups; 13 lean individuals (6 women) with BMI $<25 \mathrm{Kg} / \mathrm{m}^{2}, 10$ overweight subjects (4 women) with $30 \mathrm{Kg} / \mathrm{m}^{2}>$ BMI $\geq 25 \mathrm{Kg} / \mathrm{m}^{2}$, and 8 obese subjects ( 4 women) with BMI $>30 \mathrm{Kg} / \mathrm{m}^{2}$. Subjects provided informed written consent and the Mayo Institutional Review Board approved the study.

The application software for accessing the iPhone $3 \mathrm{G}$ accelerometer we wrote is called, "Walk "n Play" and is available to the general public at no cost from www.itunes.com [3]. The software gathers acceleration data 50 times/second in $\mathrm{x}, \mathrm{y}$ and $\mathrm{z}$ axes, and resolves the data (square root, sum of squares) to produce a measure of the user's momentary physical activity. The physical activity data are streamed to a central computer over the cell phone network to avoid filling the cell phone memory with raw accelerometer data. The user then receives direct feedback (depending on self-selected settings: second-to-second or day-today) regarding their physical activity and energy expenditure (e.g., "you burned $400 \mathrm{kcal}$ today"). 


\section{Experimental design}

The study was conducted at the Clinical Research Unit, at Mayo Clinic, which is temperature controlled and quiet. Subjects were orientated to the procedures and then weighed on a calibrated standing scale (model 644, Seca Corporation, Hanover, MD, USA) and height was measured using a stadiometer (Model 242, Seca Corporation, Hanover, MD, USA). Subjects were asked to abstain from taking alcohol for at least 12 hours prior to the start of the study. Subjects fasted, had not undertaken exertional activity and had not consumed caffeine for $>6$ hours. Throughout the study, subjects were in thermal comfort $\left(68-74^{\circ} \mathrm{F} ; 20-23^{\circ} \mathrm{C}\right)$.

Subjects wore the Physical Activity Monitoring System (PAMS) suit (Figure 1). This validated system allows body posture and physical activity to be measured every half second continuously and has been validated against both room calorimetry and doubly labeled water. The PAMS involves wearing Lycra-spande ${ }^{\circledR}$ undergarments into which are integrated four inclinometers (Crossbow Technology, Inc, San Francisco, CA) that measure body angle on the right and left lateral aspect of the torso, and the right and left lateral aspect of the mid-thigh. In addition, there are two accelerometers (Crossbow Technology, Inc, San Francisco, CA) placed at the base of the spine. There are also two data loggers (Crossbow Technology, Inc, San Francisco, CA) worn around the waist. The PAMS weighs $~ 1000$ grams.

Subjects also wore an iPhone positioned against the back (Figure 1). Relaxed subjects lay supine and awake with their head at a $10^{\circ}$ tilt. First subjects rested for 30 minutes and then resting energy expenditure was measured for 30 minutes. The order of activities was fixed and standardized throughout the experiment, as follows. Energy expenditure was measured for 20 minutes each under the following conditions

- Sitting. Subjects were seated in a backed, armed office-chair with their back, arms and legs supported. Subjects were asked to remain relaxed during the measurement.

- Standing motionless. Subjects were instructed to stand motionless with arms hanging by their sides and feet spaced 6 inches apart. Subjects were asked to remain relaxed and still during the measurement.

- Walking energy expenditure was then measured for 15 minutes each at $0.5,1,1.5$, 2, 2.5, 3 and $3.5 \mathrm{mph}$ while subjects walked on a calibrated treadmill (True 600, O'Fallon, MO, USA).

We note that cell phones are often stored in different loci such as pockets, handbags and backpacks. Although in this experiment our primary intent was to examine the accuracy and precision of the cell phone accelerometer as a measurement tool, we conducted separate studies to examine cell phone placement in a subset of 11 subjects. Here, the iPhone was attached to various locations on a subject's body: waist, arm, hand, trouser pocket as well as in their handbag and a backpack. Accelerometer output was compared but energy expenditure measurements were not repeated.

Indirect calorimetry-Measurements of energy expenditure were performed using a high precision indirect calorimeter (Columbus Instruments, $\mathrm{OH}$ ) as described previously [4]. Expired air was collected using a full-face transparent dilution mask (Scott Aviation, Lancaster, NY connected to the calorimeter by leak-proof tubing (Vacumed, Ventura, CA). We have found [5] that while wearing this equipment volunteers can complete tasks inside and outside the laboratory such as walking on level ground, climbing stairs in stairwells or working in an office environment and even in these circumstances highly precise measures of energy expenditure can be made. Repeated alcohol burn experiments yielded $\mathrm{CO}_{2}$ and $\mathrm{O}_{2}$ 
recoveries of $>98 \%$. The SD of the respiratory quotient for the last 15 minutes of the resting measurements was $<1 \%$ of the mean.

\section{Statistical analysis}

Mean energy expenditure for each phase of activity was calculated. All values are provided as mean \pm SD. ANOVA (energy expenditure, age, sex, and BMI) and post-hoc paired t-tests were used to compare paired changes in energy expenditure for the 31 subjects.

To examine our hypotheses that the cell phone-application was accurate and reliable for measuring physical activity compared to PAMS in the laboratory setting and also in predicting energy expenditure, regression analyses were used comparing the physical activity as measured by the cell phone against that measured by PAMS. Statistical significance was defined as, $\mathrm{P}<0.05$.

\section{Results}

Thirty-one subjects (14 women), $33 \pm$ (SD) 9 years, $81 \pm 20 \mathrm{~kg}$ and BMI $27 \pm 5 \mathrm{~kg} / \mathrm{m}^{2}$ completed the study. All subjects tolerated the procedures without problem or complaint. Of these 31 participants, 13 were lean $\left(23+1 \mathrm{~kg} / \mathrm{m}^{2}, 29+7\right.$ years $), 10$ were overweight $(27+1$ $\mathrm{kg} / \mathrm{m}^{2}, 34+10$ years) and 8 had obesity $\left(35+3 \mathrm{~kg} / \mathrm{m}^{2}, 39+8\right.$ years) (Table 1$)$.

The total numbers of lines of data were 210,000 this represented 2,730,000 movements captured over 13 axes (10 axes from PAMS and 3 axes on the cell phone accelerometer). Sensor determination of body posture using PAMS was correct for the 93 measurements of posture compared to observer response. There were log linear relationships between accelerometer output and velocity with $\mathrm{r}^{2}>0.98$ in all cases. The relationship between the paired accelerometers showed an Intraclass Correlation Coefficient (ICC) of 0.99. All data are gathered in duplicate as the sensors are paired and there was $>99 \%$ concordance between the matched data pairs.

We found that in all the 31 subjects, the cell phone accelerometer was able to distinguish change in walking activity reliably even with $1 / 2 \mathrm{mph}$ increments in walking. For all the subjects there were progressive increases in the cell phone accelerometer's output with increases in walking velocity $\left(\mathrm{r}^{2}>0.9, \mathrm{p}<0.001\right)$. To test our first hypothesis, we compared the cell phone accelerometer's output with that measured by the PAMS. We found that the cell phone accelerometer reliably sensed sedentary and walking activity at different speeds and was accurate and precise as compared to the PAMS, with intra-class correlation coefficient $\left(\mathrm{r}^{2}>0.98\right)$ (Figure 2). The relationships between the cell phone accelerometer output and energy expenditure were consistent across the weight categories (Figure 2).

We examines, in a subset of 11 subjects ( 3 women, 8 men), $25.2 \pm 4.8$ years, $72.8 \pm 4.5 \mathrm{Kg}$ and body mass index of $23.6 \pm 3.2 \mathrm{~kg} / \mathrm{m}^{2}$, the physical activity measured by the cell phone placed on various body positions mentioned earlier in order to be able to correct for the placement issue. We found that the physical activity measured by the cell phone placed at different body positions correlated well with the physical activity measured at the back (Table 2). However, the lines of regression of were different. This suggests that individual prediction of energy expenditure would be improved with the intelligence of understanding where the cell phone is located on the person. However, documenting bouts of activity versus sedentariness would not be effected by the cell phones location; at least in these small studies.

As expected, the resting as well as walking energy expenditure, expressed in absolute terms was significantly less in the lean compared to the obese participants. When corrected for the 
body weight, resting as well as walking energy expenditure was significantly greater in the lean compared to the obese (Table 1). The energy expenditure showed a significant linear response to progressive increases in walking velocity for all the participants $\left(r^{2}>0.98\right.$, $\mathrm{p}<0.001$ ). To address this hypothesis, the data demonstrated that energy expenditure increased significantly with every increase in walking velocity irrespective of whether it was represented in absolute terms or corrected for body weight. The cell phone accelerometer's output also showed a significant linear response while detecting walking energy expenditure for all subjects (Figure 3$)\left(r^{2}>0.9, p<0.001\right)$.

\section{Feasibility of widespread deployment}

We released the Walk n' Play iPhone-Application to the public through www.itunes.com for 4 months. In that time, there were 3,018 male users and 4,328 female users. Self-reported age was $33+11$ years and weight, $80+20 \mathrm{~kg}$. Interestingly, $98 \%$ of users used the Application in self monitoring mode (i.e.; as the self-feedback tool as we propose here). The distribution of daily activity for 7346 users is shown in (Figure 4). We found that most daily activity detected with the cell phone accelerometer occurs in the low intensity range (i.e. non-exercise activity).

\section{Discussion}

Physical activity benefits many aspects of health as well as weight control [6] e.g. diabetes, hypertension, cardiovascular diseases as well as cancer prevention [7,8]. Accelerometers and step counters are available as adjunct technologies to daily life to help people measure and modulate their daily physical activity $[9,10]$. Here we are interested in embedding activitysensing technologies into everyday devices that people are already carrying. In this paper we describe the development and laboratory validation of an accelerometer embedded into a cell phone platform and its application for energy expenditure determination.

We validated the accuracy of an accelerometer embedded in to a cell phone platform, by collecting physical activity data in lean, overweight and obese individuals and comparing these data with a Gold Standard - The Physical Activity Monitoring System (PAMS). The cell phone accelerometer performed well and showed accurate, reproducible and excellent linearity of response with increasing ambulation. We performed studies in a subset of subjects to examine placement because people carry their cell phones in different places such as pockets and backpacks). The data demonstrated that cell phone placement is important. To dissect human energy expenditure in an individual and maximize accuracy, positional intelligence would be beneficial. However, these studies were too small to quantify to what degree. Nonetheless, even when corrected for different placement positions, the data from this study demonstrate that the cell phone accelerometer provides remarkably accurate and reliable data on physical activity albeit noting the study's limitations.

The idea of harnessing a cell phone's accelerometer to detect gait and movement has been engineered before [11]. However, the human validation we describe against calorimetry is novel and we the deployment and data mining from the Application are novel. Herein we describe, for the first time, the potential application of cell phone accelerometer for mass public assessments of energy expenditures.

The notion of building ubiquitous electronic platforms to promote physical activity seems attractive, especially noting first, the prevalence of obesity [12]; second, the wide availability of electronic devices in the population. It is important to note too that with a broadening understanding of the social influences on obesity [13], electronic platforms may wisely deliver more than energy balance modulation alone [14]. For example, multiple 
therapeutic regimens include physical activity prescription and might benefit from this capability of monitoring a patient's adherence to the prescribed regimen. This is germane not only to weight management but might also include the care of patients with diabetes, hypertension, hyperlipidemia, cardiovascular disease, sleep disorders, back pain and stroke $[15,16]$. Moreover, the social networking elements available in the system we tested enables the patient to connect with the healthcare staff and seek guidance with regards to nutrition counseling and improved therapy [14].

The study had its limitations we acknowledge. First, the study was performed under laboratory setting and not in a free-living environment. However, our objective in this undertaking was to assess whether the cell phone accelerometer provides an accurate and precise data under optimal conditions. The data were sufficiently exciting to suggest that free-living studies are now warranted. Second, while we studied 31 participants, we did not include the elderly or children. Further studies will expand the study populations as these results are sufficiently encouraging to warrant this. A third limitation is that many people do not have access to this particular cell phone platform. In fact, of $>275$ million cell phone subscribers in the US [17], only 20 million have iPhones [18]. What is noteworthy however is that these 2 million people are carrying a likely-valid activity-sensing technology that could be exploited for health. Our hope is that if this approach is successful, the marketplace will drive broadened embedded activity-sensing technologies (the MEMS, for example) across multple mobile platforms.

With the omnipresent problem of sedentariness, overweight and obesity across the world, it is hoped that integrating activity-sensing technologies into everyday electronics devices will enable people to increase their daily physical activity, improve their weight and health.

\section{Acknowledgments}

Grants: The project described was supported by grants DK63226, DK66270, DK50456 (Minnesota Obesity Center) and Grant Number 1 UL1 RR024150 from the National Center for Research Resources (NCRR), a component of the National Institutes of Health (NIH), and the NIH Roadmap for Medical Research. Its contents are solely the responsibility of the authors and do not necessarily represent the official view of NCRR or NIH. Information on NCRR is available at http://www.ncrr.nih.gov/. Information on Reengineering the Clinical Research Enterprise can be obtained from http://nihroadmap.nih.gov.

\section{References}

1. FAO. Human energy requirements. FAO Food and Nutrition Technical Report Series; Report of a Joint FAO/WHO/UNU Expert Consultation; Rome. 17-24 October 2001; Rome: FAO; 2004.

2. Plasqui G, Westerterp KR. Accelerometry and heart rate as a measure of physical fitness: proof of concept. Med Sci Sports Exerc. 2005; 37:872-876. [PubMed: 15870644]

3. Apple Computers. iTunes. Cupertino: 2009.

4. Levine JA, Lanningham-Foster LM, Krizan AC, Olson LR, Kane PH, et al. Interindividual variation in posture allocation: possible role in human obesity. Science. 2005; 307:584-586. [PubMed: 15681386]

5. Levine JA, Schleusner SJ, Jensen MD. Energy expenditure of nonexercise activity. Am J Clin Nutr. 2000; 72:1451-1454. [PubMed: 11101470]

6. Ravussin E, Bogardus C. A brief overview of human energy metabolism and its relationship to essential obesity. Am J Clin Nutr. 1992; 55:242-245.

7. Saris WH, Blair SN, van Baak MA, Eaton SB, Davies PS, et al. How much physical activity is enough to prevent unhealthy weight gain? Outcome of the IASO 1st Stock Conference and consensus statement. Obes Rev. 2003; 4:101-14. [PubMed: 12760445]

8. Blair SN, LaMonte MJ, Nichaman MZ. The evolution of physical activity recommendations: how much is enough? Am J Clin Nutr. 2004; 79:913-920. 
9. Chen KY, Bassett DR Jr. The technology of accelerometry-based activity monitors: current and future. Med Sci Sports Exerc. 2005; 37:490-500.

10. Chen KY, Acra SA, Majchrzak K, Donahue CL, Baker L, et al. Predicting energy expenditure of physical activity using hip- and wrist-worn accelerometers. Diabetes Technol Ther. 2003; 5:10231033. [PubMed: 14709206]

11. Hynes M, Wang H, Kilmartin L. Off-the-shelf mobile handset environments for deploying accelerometer based gait and activity analysis algorithms. Conf Proc IEEE Eng Med Biol Soc. 2009; 2009:5187-5190. [PubMed: 19964383]

12. James WP. The epidemiology of obesity: the size of the problem. J Intern Med. 2008; 263:336352. [PubMed: 18312311]

13. Franzini L, Elliott MN, Cuccaro P, Schuster M, Gilliland MJ, et al. Influences of Physical and Social Neighborhood Environments on Children's Physical Activity and Obesity. Am J Public Health. 2008; 99:271-278. [PubMed: 19059864]

14. McCrady-Spitzer SK, Levine JA. Integrated electronic platforms for weight loss. Expert Rev Med Devices. 2010; 7:201-207. [PubMed: 20214426]

15. Bijnen FC, Feskens EJ, Caspersen CJ, Nagelkerke N, Mosterd WL, et al. Baseline and previous physical activity in relation to mortality in elderly men: the Zutphen Elderly Study. Am J Epidemiol. 1999; 150:1289-1296. [PubMed: 10604771]

16. Karmisholt K, Gotzsche PC. Physical activity for secondary prevention of disease. Systematic reviews of randomised clinical trials. Dan Med Bull. 2005; 52:90-94. [PubMed: 16009053]

17. CTIA. CTIA Survey Midyear 2009. CTIA-The Wireless_Association®; 2009.

18. Apple Computers. Second Quarter Sales Report.ns. 2009. 


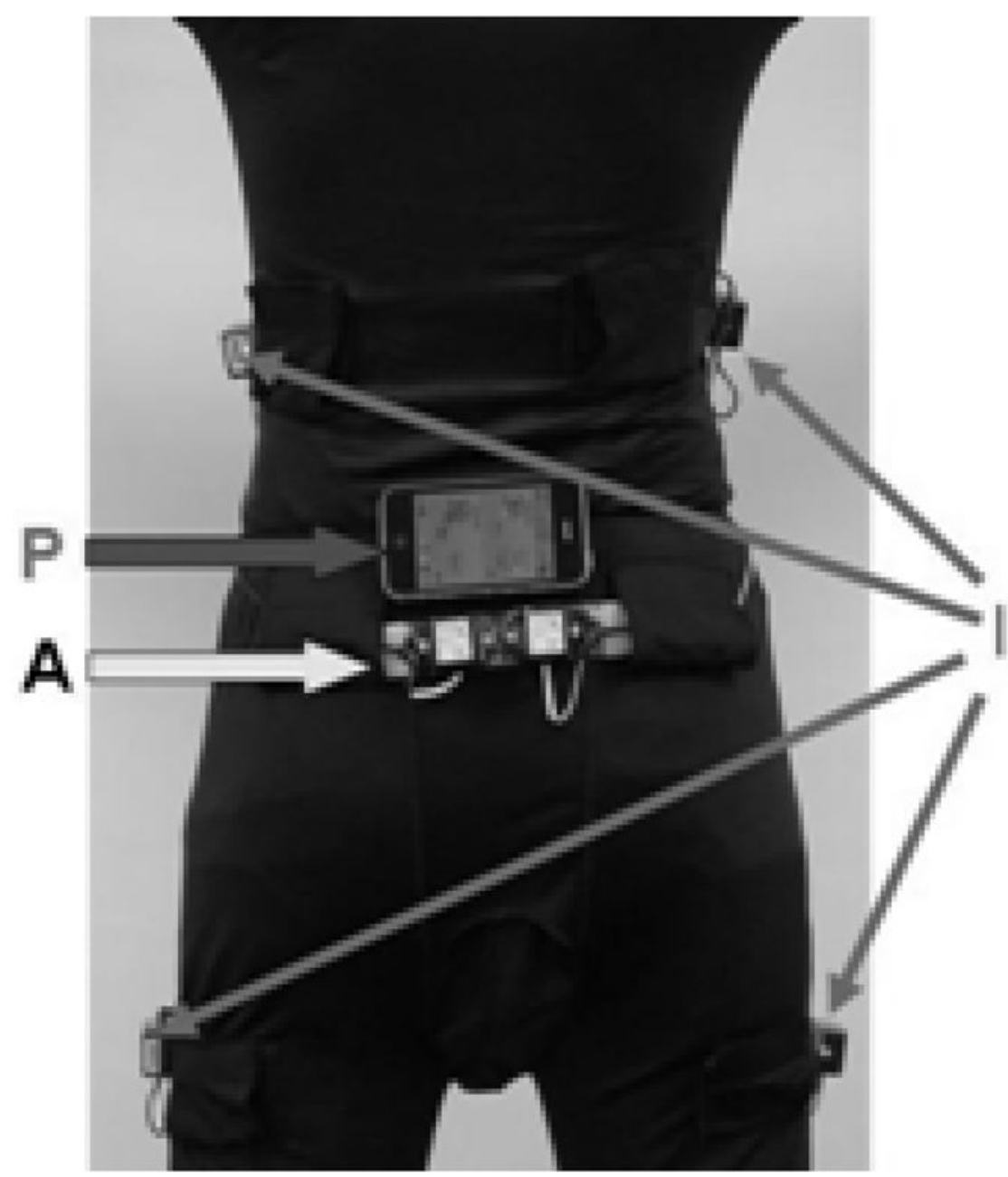

Figure 1.

The complete sensor system used in this study comprises of a cell phone (iPhone, Apple Computer, Cupertino, CA) (P) and the Physical Activity Monitoring Suit (PAMS) which comprises 4 inclinometers (I); 2 tri-axial accelerometers (A) and two data loggers. 


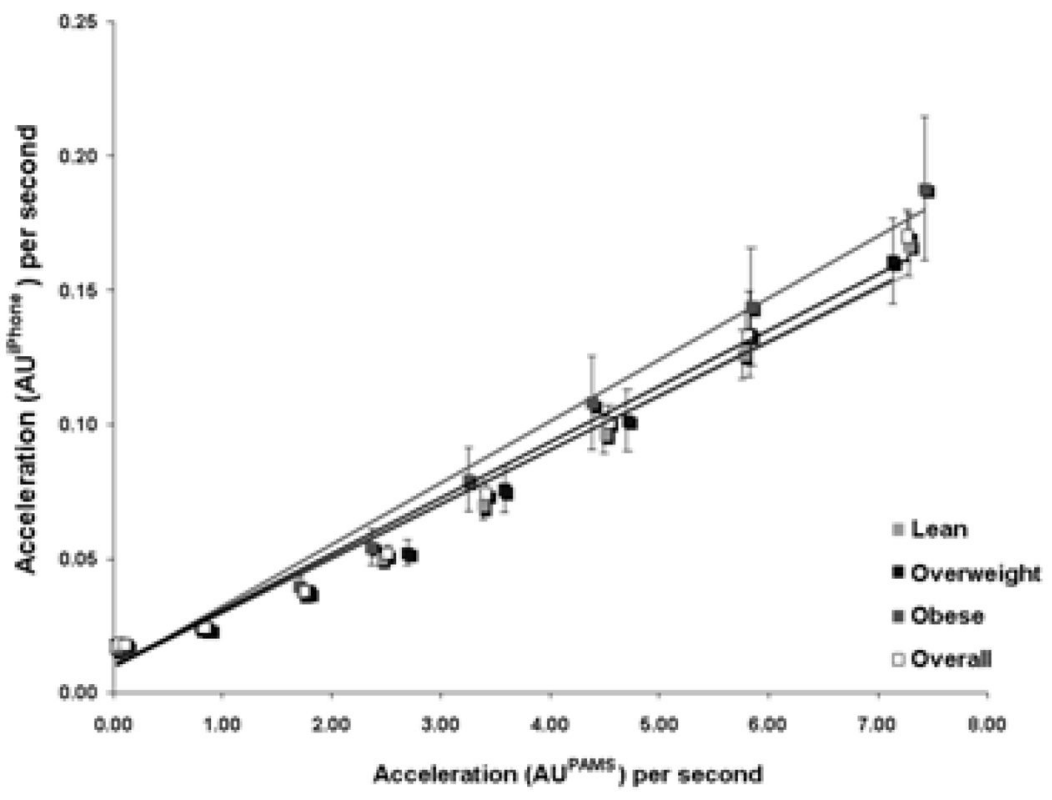

Figure 2.

Cell phone accelerometer output (AU iPhone) versus PAMS accelerometer output (AU PAMS) for 31 study participants (13 Lean, 10 Overweight, 8 Obese). Data are shown as Mean \pm SD. The first data point whereas the subsequent data points refer to incremental walking velocities. 


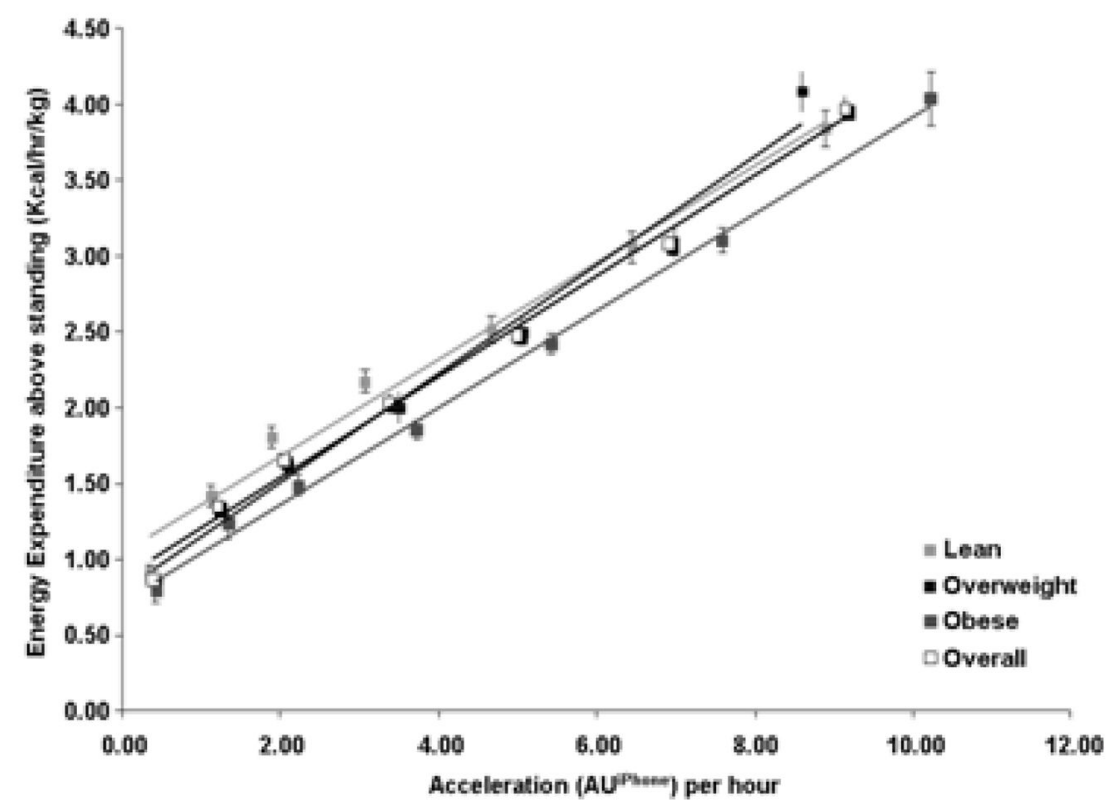

Figure 3.

Change in energy expenditure relative to body mass above standing while walking at $1,1.5$ $2,2.5,3,3.5 \mathrm{mph}$ versus the cell phone accelerometer output, in acceleration units (AU iPhone) for 31 study participants (13 Lean, 10 Overweight, 8 Obese). Data are shown as Mean \pm SD. 


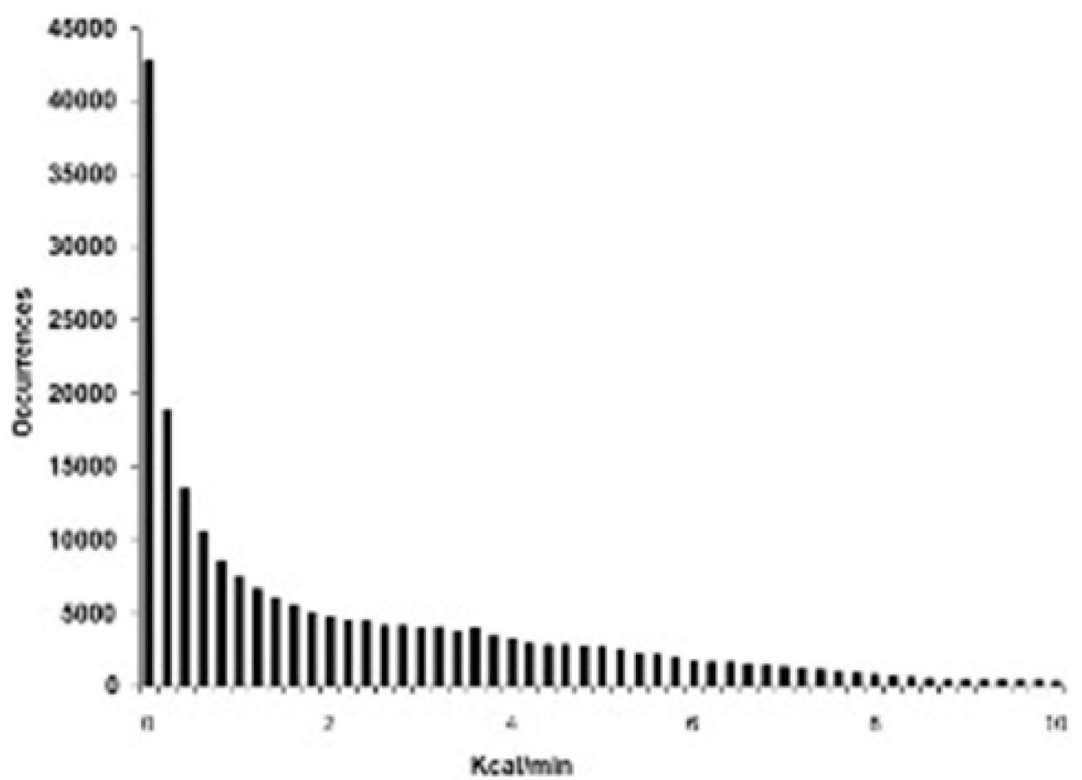

Figure 4.

Cell phone Application data for 7346 iPhone users. 


\section{Table 1}

Characteristics of study subjects. Data are expressed as mean \pm SD.

\begin{tabular}{|c|c|c|c|c|}
\hline & TOTAL & Lean & Overweight & Obese \\
\hline N (men; women) & 31 & $13(7: 6)$ & $10(6: 4)$ & $8(4: 4)$ \\
\hline Weight (kg) & $81 \pm 20$ & $67 \pm 10$ & $79 \pm 11$ & $106 \pm 19$ \\
\hline BMI $\left(\mathrm{kg} / \mathrm{m}^{2}\right)$ & $27 \pm 5$ & $23 \pm 1$ & $27 \pm 1$ & $35 \pm 3$ \\
\hline $\begin{array}{l}\text { Age (years) } \\
\text { Energy expenditure (kcal/hr) }\end{array}$ & $33 \pm 9$ & $29 \pm 7$ & $34 \pm 10$ & $39 \pm 8$ \\
\hline Resting & $77 \pm 12$ & $74 \pm 12$ & $78 \pm 13$ & $82 \pm 11$ \\
\hline Sitting & $83 \pm 16$ & $82 \pm 16$ & $85 \pm 19$ & $85 \pm 13$ \\
\hline Standing & $89 \pm 17$ & $86 \pm 16$ & $93 \pm 22$ & $89 \pm 8$ \\
\hline Walking: $0.5 \mathrm{mph}$ & $158 \pm 25$ & $146 \pm 25$ & $162 \pm 30$ & $171 \pm 10$ \\
\hline Walking: $1 \mathrm{mph}$ & $196 \pm 33$ & $180 \pm 30$ & $200 \pm 39$ & $216 \pm 15$ \\
\hline Walking: $1.5 \mathrm{mph}$ & $220 \pm 33$ & $205 \pm 30$ & $220 \pm 39$ & $244 \pm 16$ \\
\hline Walking: $2 \mathrm{mph}$ & $251 \pm 45$ & $230 \pm 29$ & $251 \pm 45$ & $287 \pm 49$ \\
\hline Walking: $2.5 \mathrm{mph}$ & $288 \pm 57$ & $252 \pm 35$ & $291 \pm 54$ & $344 \pm 45$ \\
\hline Walking: $3 \mathrm{mph}$ & $338 \pm 74$ & $289 \pm 39$ & $338 \pm 62$ & $417 \pm 64$ \\
\hline Walking: $3.5 \mathrm{mph}$ & $410 \pm 94$ & $342 \pm 50$ & $417 \pm 76$ & $513 \pm 68$ \\
\hline \multicolumn{5}{|c|}{ Energy expenditure/weight (kcal/kg/hr) } \\
\hline Resting & $0.98 \pm 0.15$ & $1.10 \pm 0.08$ & $0.98 \pm 0.10$ & $0.78 \pm 0.06$ \\
\hline Sitting & $1.06 \pm 0.21$ & $1.22 \pm 0.13$ & $1.06 \pm 0.13$ & $0.81 \pm 0.12$ \\
\hline Standing & $1.14 \pm 0.22$ & $1.28 \pm 0.12$ & $1.17 \pm 0.16$ & $0.85 \pm 0.10$ \\
\hline Walking: $0.5 \mathrm{mph}$ & $2.01 \pm 0.33$ & $2.19 \pm 0.24$ & $2.05 \pm 0.19$ & $1.65 \pm 0.32$ \\
\hline Walking: $1 \mathrm{mph}$ & $2.49 \pm 0.39$ & $2.7 \pm 0.28$ & $2.53 \pm 0.29$ & $2.09 \pm 0.35$ \\
\hline Walking: $1.5 \mathrm{mph}$ & $2.79 \pm 0.41$ & $3.09 \pm 0.29$ & $2.78 \pm 0.27$ & $2.34 \pm 0.26$ \\
\hline Walking: $2 \mathrm{mph}$ & $3.17 \pm 0.40$ & $3.46 \pm 0.28$ & $3.17 \pm 0.30$ & $2.71 \pm 0.19$ \\
\hline Walking: $2.5 \mathrm{mph}$ & $3.62 \pm 0.37$ & $3.8 \pm 0.35$ & $3.66 \pm 0.31$ & $3.27 \pm 0.23$ \\
\hline Walking: $3 \mathrm{mph}$ & $4.21 \pm 0.36$ & $4.34 \pm 0.37$ & $4.26 \pm 0.33$ & $3.96 \pm 0.28$ \\
\hline Walking: $3.5 \mathrm{mph}$ & $5.11 \pm 0.45$ & $5.12 \pm 0.41$ & $5.25 \pm 0.40$ & $4.90 \pm 0.54$ \\
\hline
\end{tabular}




\section{Table 2}

Regression parameters and correlation coefficients of the linear regression equation for physical activity measured at waist against different body locations.

\begin{tabular}{|l|c|c|c|}
\hline \multirow{2}{*}{ iPhone placement } & \multicolumn{2}{|c|}{$\mathbf{y}=\mathbf{m x}+\mathbf{c}$} & \multirow{2}{*}{} \\
\cline { 2 - 3 } & Slope(m) & Intercept (c) & $\mathbf{r}^{\mathbf{2}}$ \\
\hline Arm & 0.77 & 1.23 & 0.65 \\
\hline Hand & 0.89 & 0.46 & 0.73 \\
\hline Pants Pocket & 0.96 & 0.61 & 0.88 \\
\hline Backpack & 0.99 & -0.39 & 0.82 \\
\hline Jacket Side Pocket & 0.97 & 0.19 & 0.89 \\
\hline Jacket Front Pocket & 0.99 & -0.27 & 0.84 \\
\hline Handbag & 0.96 & 0.39 & 0.91 \\
\hline
\end{tabular}

